\title{
Correction to: Rates of TP53 Mutation are Significantly Elevated in African American Patients with Gastric Cancer
}

Elke J. A. H. van Beek, MD ${ }^{1}$, Jonathan M. Hernandez, MD ${ }^{1,2}$, Debra A. Goldman, $\mathrm{MS}^{3}$, Jeremy L. Davis, $\mathrm{MD}^{1,2}$, Kaitlin C. McLoughlin, $\mathrm{MD}^{2}$, R. Taylor Ripley, $\mathrm{MD}^{2}$, Teresa $\mathrm{S}$. Kim, $\mathrm{MD}^{1}$, Laura H. Tang, MD, $\mathrm{PhD}^{4}$, Jaclyn $\mathrm{F}$. Hechtman, $\mathrm{MD}^{4}$, Jian Zheng, $\mathrm{MD}^{1}$, Marinela Capanu, $\mathrm{PhD}^{3}$, Nikolaus Schultz, $\mathrm{PhD}^{3,5,6}$, David M. Hyman, $\mathrm{MD}^{7}$, Marc Ladanyi, $\mathrm{MD}^{4,5}$, Michael F. Berger, $\mathrm{PhD}^{4,5,6}$, David B. Solit, $\mathrm{MD}^{5,6,7}$, Yelena Y. Janjigian, $\mathrm{MD}^{7}$, and Vivian E. Strong, MD, FACS ${ }^{1}$

${ }^{1}$ Department of Surgery, Gastric and Mixed Tumor Service, Memorial Sloan-Kettering Cancer Center, New York, NY; ${ }^{2}$ National Cancer Institute, National Institutes of Health, Bethesda, MD; ${ }^{3}$ Department of Epidemiology \& Biostatistics, Memorial Sloan-Kettering Cancer Center, New York, NY; ${ }^{4}$ Department of Pathology, Memorial Sloan-Kettering Cancer Center, New York, NY; ${ }^{5}$ Human Oncology and Pathogenesis Program, Memorial Sloan-Kettering Cancer Center, New York, NY; ${ }^{6}$ Marie-Josée \& Henry R. Kravis Center for Molecular Oncology, Memorial Sloan-Kettering Cancer Center, New York, NY; ${ }^{7}$ Department of Medicine, Memorial Sloan Kettering Cancer Center, Weill Cornell Medical College, New York, NY

\section{CORRECTION TO:}

ANN SURG ONCOL (2018) 25:2027-2033

https://doi.org/10.1245/s10434-018-6502-x

In the original article Kaitlin C. McLoughlin's name is spelled incorrectly. It is correct as reflected here.
Publisher's Note Springer Nature remains neutral with regard to jurisdictional claims in published maps and institutional affiliations.

The original article can be found online at https://doi.org/10.1245/ s10434-018-6502-x.

(C) Society of Surgical Oncology 2020

Published Online: 2 January 2020

V. E. Strong, MD, FACS

e-mail: strongv@mskcc.org 